\title{
Cambios en la epidemiología de las hepatitis virales en Chile y consideraciones en estrategias de prevención
}

\author{
H umberto Ibarra V1. \\ The changing epidemiology \\ of viral hepatitis in Chile
}

The social and sanitary changes that Chile is experiencing will change the epidemiologic profile of viral hepatitis. Virus A hepatitis will displace to older ages, and immunization plans with specific vaccines should be considered. The real prevalence of hepatitis B may be higher, due to an underreporting of the disease. The education and vaccination of high risk groups should be reinforced. E virus hepatitis requires more research in risk groups and in certain animal species consumed by humans. $C$ virus hepatitis is the greatest challenge as it causes chronic liver disease and is the main cause for liver transplantation (Rev Méd Chile 2007; 135: 229-39).

(Key words: Hepatitis A, Hepatitis B; Hepatitis C; Hepatitis E; Viral hepatitis vaccines)

Recibido el 20 de noviembre, 2006. Aceptado el 28 de noviembre, 2006.

Manuscrito preparado por invitación de los Editores.

${ }^{1}$ Instituto de Medicina, Facultad de Medicina, Universidad Austral de Chile. Valdivia, Chile.

$\mathrm{H}$ asta el presente se han identificado 5 virus causantes de hepatitis en el hombre designándoseles con las letras: $\mathrm{A}, \mathrm{B}, \mathrm{C}, \mathrm{D}$ y $\mathrm{E}$, respectivamente. Sin embargo, a pesar del avance en las técnicas de investigación, aún permanecen casos de hepatitis sin etiología detectable, que se agrupan como «epatitis no A-E».

En Chile, la hepatitis viral sigue siendo un importante problema de salud, pero cambios en diversos estándares socio-sanitarios y culturales en los últimos años, han modificado en nuestro país la importancia relativa de estos agentes.

Correspondencia a: Dr. Humberto Ibarra V. Casilla 567 Universidad Austral de Chile. Valdivia, Chile. Fax: 56-63-221995. E mail: hibarra@uach.cl
HePATITIS A

Siendo su principal vía de transmisión feco-oral, su importancia está en estrecha relación con las condiciones sanitarias y culturales de una población. En este sentido, tanto la prevalencia como la incidencia de la hepatitis A podrían representar un índice del desarrollo socio-económico de una determinada región geográfica.

En 1975, el virus A era la causa principal de hepatitis en Chile. Por grupos etarios, 30\% afectaba a niños entre 0 y 4 años de edad. Sin embargo, datos de notificación del año 2005, del Ministerio de Salud, informan actualmente sólo 10\%. En este mismo periodo de 30 años, se observa un aumento de $5 \%$ a $30 \%$ en edades entre 15 y 24 años (Figura 1). Esta modificación está revelando un evidente desplazamiento de la enfermedad a edades superiores. 


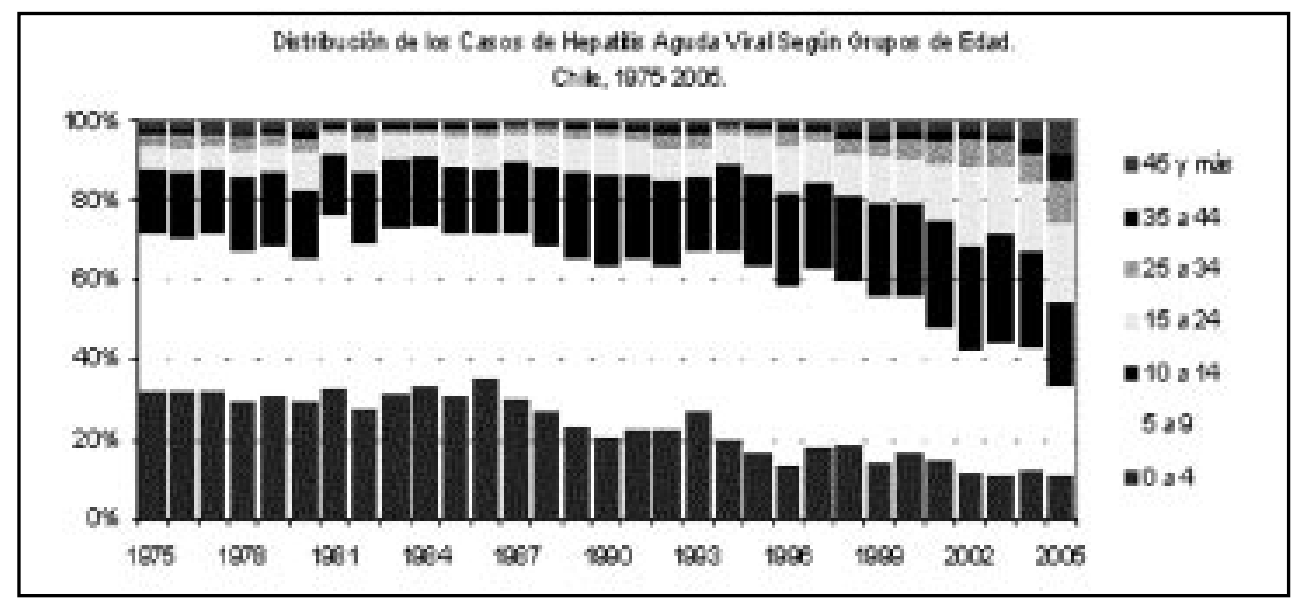

Figura 1. Distribución porcentual de hepatitis aguda por rangos de edad, en Chile.

Por otro lado, también en la última década, se ha producido un descenso en las tasas de hepatitis A. En el año 1998 hubo 5.796 notificaciones con una tasa para Chile de 39,1 por 100.000 habitantes, en cambio el año 2005 bajó a 2.302 notificaciones con una tasa de 14,21. Los años 2002 y 2003 se consideran años epidémicos, puesto que escaparon de la tendencia a la baja que se venía observando previamente (Figura 2). Este fenómeno podría explicarse por una menor preocupación de la población respecto a cuidados higiénicos personales o manipulación de alimentos y, por otro lado, por adquirir más tardíamente inmunidad natural»a la hepatitis A. Como se sabe, la gran mayoría de los individuos desarrolla inmunidad por contacto con el virus, sin evidencias de enfermedad clínica. En países en transición epidemiológica como el nuestro, el contacto con el virus A se ha retardado respecto a las décadas anteriores y de esta manera la población tiene más riesgo de infección a edades más tardías, más sintomáticas y por brotes epidémicos. Las campa-

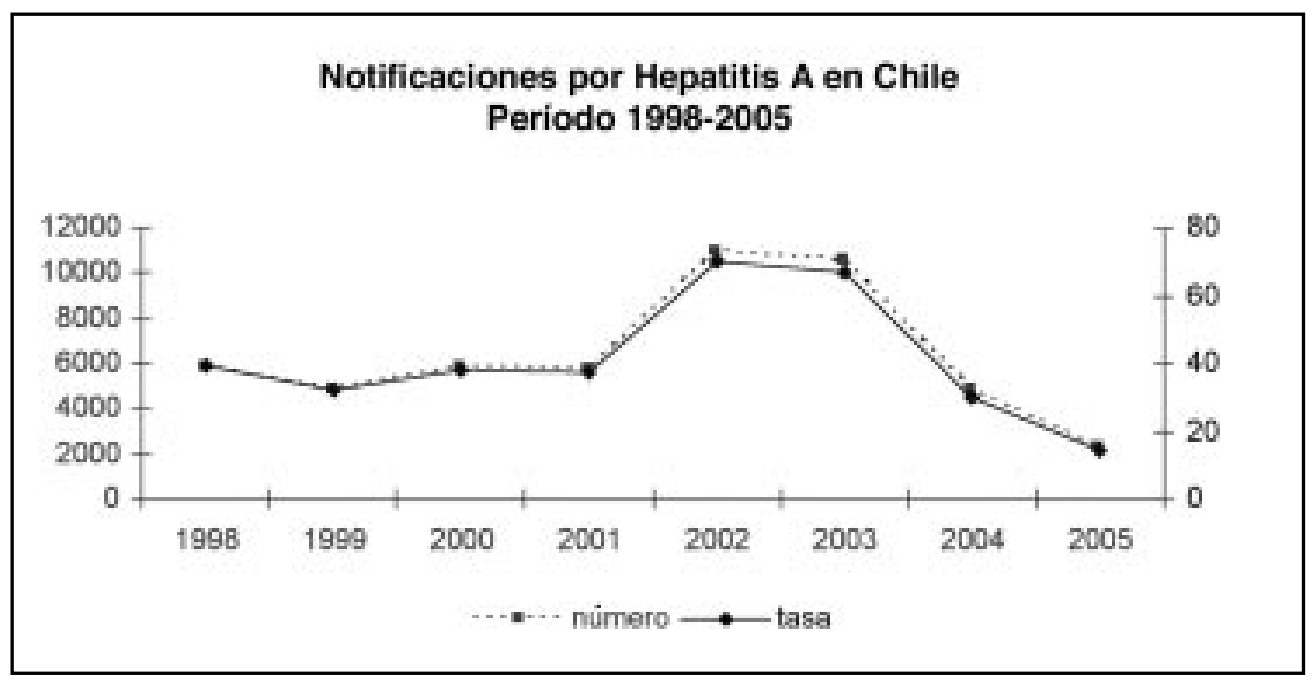

Figura 2. Número y tasa de notificaciones de hepatitis A, en Chile (1998-2005). 
ñas sanitarias a propósito del cólera jugaron un importante rol en la caída de las tasas de hepatitis en los últimos 3 años (2003, 2004, 2005). En un estudio de hepatitis aguda en adultos chilenos en el sur del país a fines de los 90, se comunicó el desplazamiento de la incidencia de hepatitis a edades mayores ${ }^{2}$.

Si bien la tasa para Chile en 2005 fue 14,2 por 100.000 habitantes, hubo marcadas diferencias regionales. En la zona norte, la Región de Tarapacá sobrepasó los 80 x 100.000. En cambio en la zona austral, la Región de Magallanes presentó una tasa bajo 5 x 100.000 (Figura 3).

Diversas investigaciones en el país permiten demostrar una clara tendencia a la disminución de la prevalencia de anti-VHA, tanto en población infantil como adulta. En niños de bajo estrato social en Santiago de Chile, Zacarías ${ }^{3}$ comunicó $^{2}$ altísima prevalencia en los años 80. Un estudio similar efectuado por Lagos ${ }^{4}$ a fines de los 90 reportó una caída a más de la mitad (Figura 4). Del mismo modo en niños del sur de Chile se observó disminución de la prevalencia, al comparar el año 1984 (Riedemann S. comunicación personal) con los años $1988^{5}$ y $1998^{6}$, respectivamente (Figura 4).

En individuos adultos del sur de Chile, la prevalencia para anti-VHA en 1984 se acercaba a
$100 \%{ }^{7}$. Sin embargo, a fines de los 90 cayó y fue aún más baja en personal de salud ${ }^{8}$. Una reciente comunicación de prevalencia en Santiago de Chile reporta entre los años 1990 y 1998 una caída de $53,7 \%$ a 40,6\% en individuos entre 1 a 24 años de edad $^{9}$ (Figura 5).

En un reciente estudio prospectivo de niños de 4 años de bajo estrato socioeconómico se comunica una prevalencia de anti-VHA de sólo 11,3\%, de los cuales al año de seguimiento, en casi la mitad de los niños no se detectan dichos anticuerpos. Este fenómeno podría deberse a que los booster naturales por contacto ambiental con el virus A no son suficientes para mantener la inmunidad por langos períodos y por lo tanto, la tasa de anticuerpos es cada vez menor ${ }^{10}$.

Las evidencias anteriores implican que la hepatitis A en nuestro país, se desplaza a edades superiores, con inmunidad «natural» más tardía, con más individuos susceptibles de infectarse y por lo tanto, en este nuevo escenario ya no son suficientes las cuidados sanitarios para su prevención, sino debe evaluarse la aplicación de programas de vacunación, como sucede en países desarrollados.

En Chile se hizo el primer estudio latinoamericano de vacunación contra hepatitis A, publicado el año 1992. Se utilizó vacuna inactivada en

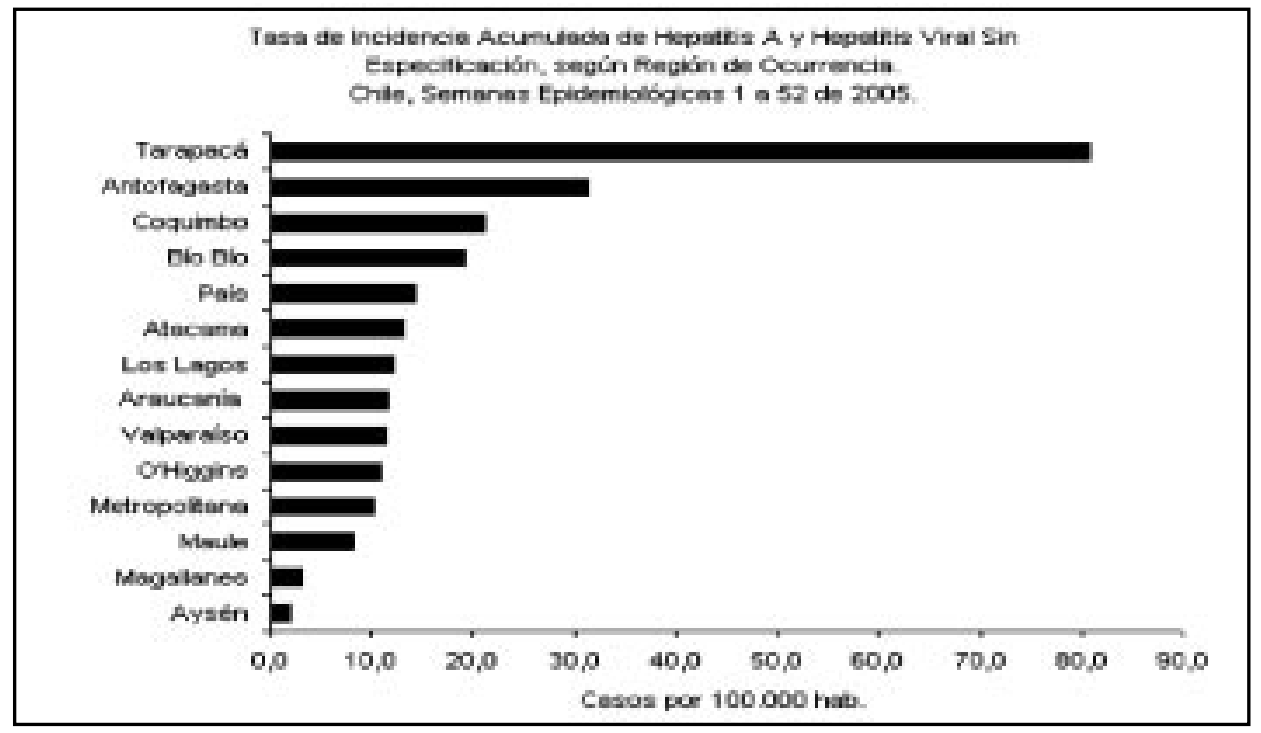

Figura 3. Tasa de hepatitis A año 2005 por regiones, en Chile. 


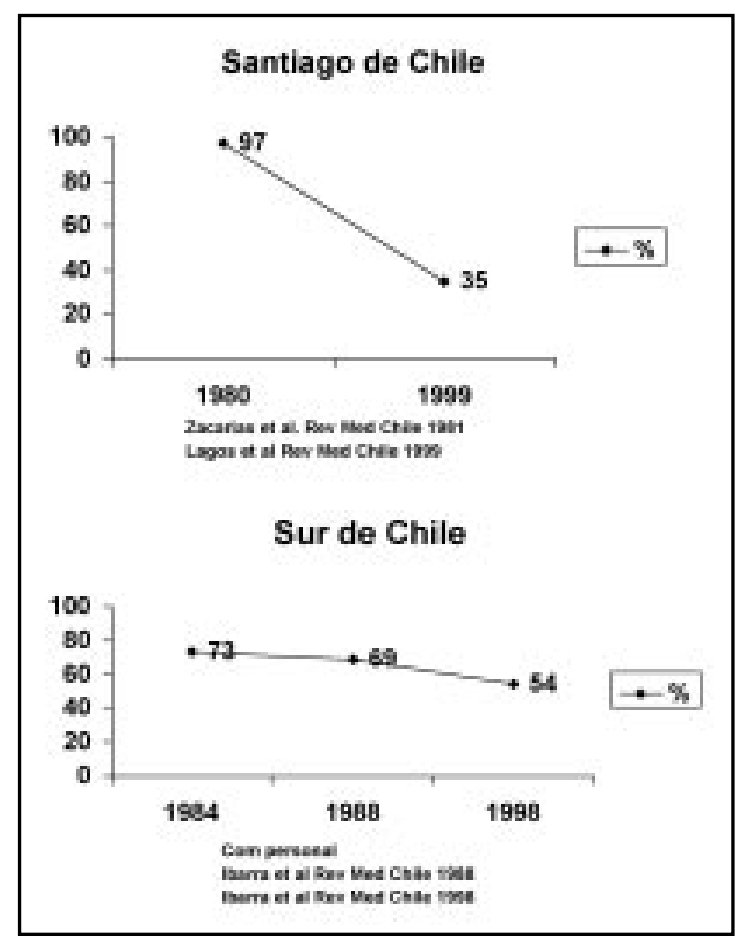

Figura 4. Modificaciones de prevalencia de anti-VHA (\%) en dos décadas en niños en Chile.

formalina ${ }^{11}$. Aplicando un esquema de vacunación 0-1-6 meses, en 124 niños de entre 6 y 15 años, se lograron títulos de anticuerpos de 2.300 $\mathrm{mIU} / \mathrm{ml}$ posteriores a la última dosis.

Un nuevo estudio publicado en 2002, también demostró la eficacia de una vacuna combinada contra virus A y B. Esta se aplicó con el mismo esquema 0-1-6 meses en 345 individuos adultos entre 18 y 40 años de edad, alcanzando títulos sobre $6.000 \mathrm{mIU} / \mathrm{ml}^{12}$.

En 2003 se reportó un estudio para evaluar la respuesta inmune en niños menores de un año anti-VHA positivos (transferencia de anticuerpos maternales) en los cuales se aplicó vacuna a los 6 meses y al año, obteniéndose primero un descenso en la tasa de anticuerpos y, luego de la dosis de refuerzo, se alcanzaron títulos protectores de alrededor de $1.800 \mathrm{mIU} / \mathrm{ml}^{13}$.

Estas vacunas liberan lentamente el antígeno del sitio de inoculación, gracias a las sales de aluminio que se utilizan como coadyuvantes.

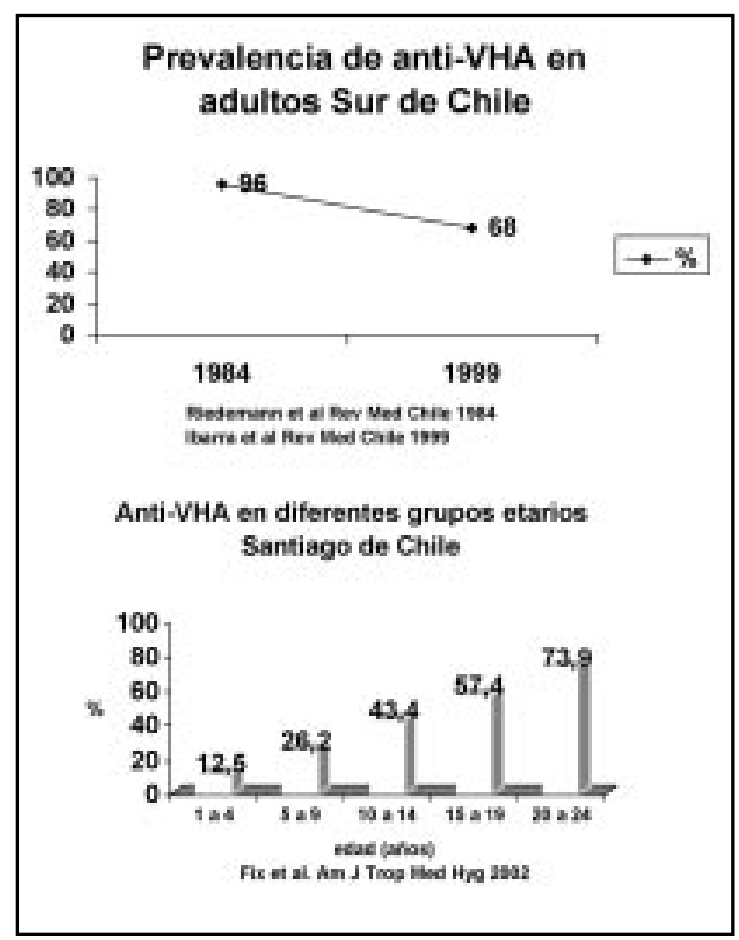

Figura 5. Anti-VHA (\%) en adultos y otros grupos etarios en Chile.

Inducen la activación del complejo mayor de histocompatibilidad y de los macrófagos y estimulan la absorción de los antígenos así como el posterior procesamiento por las células presentadoras de antígeno (CPA). Pero tienen ciertas desventajas como, por ejemplo, posible inducción de ganglios dolorosos, eritema en sitio de punción y la poca capacidad de activar una respuesta inmunológica celular más potente y duradera.

Recientemente se han desarrollado vacunas virosomales contra la hepatitis A (Epaxal ${ }^{\circledR}$ ), que tienen algunas características más ventajosas. Son vesículas esféricas con doble capa lipídica (lecitina, cefalina), 100 veces más pequeñas que las partículas contenidas en las vacunas adsorbidas sobre aluminio. En su superficie están anclados viriones de virus hepatitis A de la cepa RG-SB inactivados con formalina. Estos viriones están intercalados con hemoaglutininas (HA), neuraminidasas (NA) y glicoproteínas del virus de la gripe cepa A Singapore 6/68 (Figura 6). La HA presenta afinidad por el 


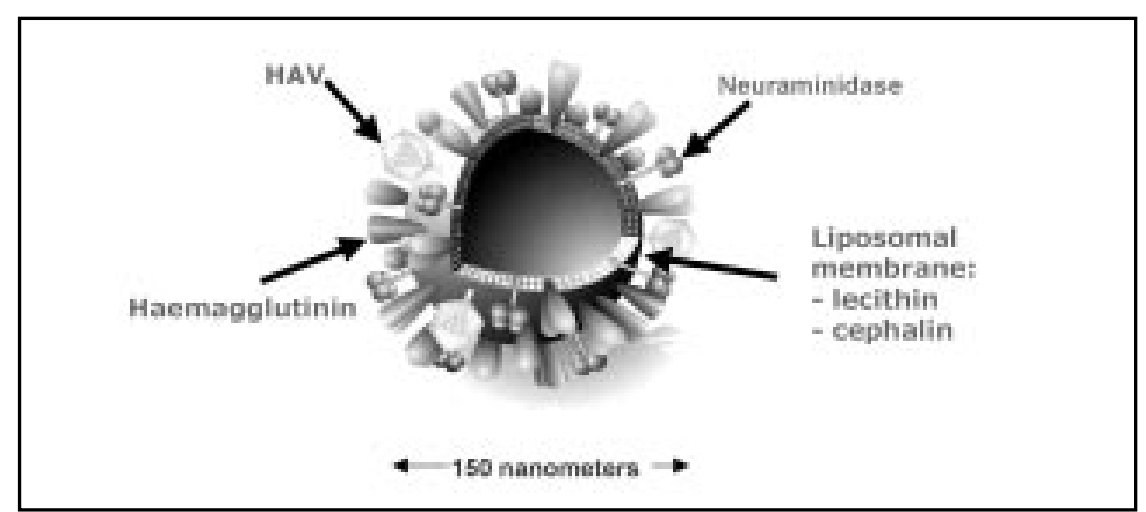

Figura 6. Vacuna virosomal contra la hepatitis A (reproducción autorizada por Epaxal ${ }^{\circledR}$ ).

ácido siálico presente en la superficie de la CPA. Después de la adhesión los viriones son endocitados, se fusionan membranas endosomales y virosomales. Posteriormente hay degradación proteica y los viriones de VHA se unen al complejo mayor de histocompatibilidad tipo II. Se expresan en la superficie induciendo la activación de linfocitos $\mathrm{T}$ helper, que mediante citoquinas estimulan la producción de anticuerpos por las células $B$, dando inicio a la respuesta inmune (Figura 7).

El primer estudio utilizando vacuna virosomal en Chile se publicó en $2004^{14}$, en que se aplicó vacuna a 20 niños de 12 a 16 meses y 80 niños y adolescentes de 5 a 17 años. Se utilizó esquema 012 meses, con buena tolerancia, obteniendo títulos de anticuerpos sobre $4.600 \mathrm{mIU} / \mathrm{ml}$ en niños pequeños y $2.800 \mathrm{mIU} / \mathrm{ml}$ en niños mayores. Resultados similares se habían obtenido en otro estudio de niños en Centroamérica ${ }^{15}$.

La eficacia de las vacunas contra la hepatitis A ha sido largamente demostrada; sin embargo persiste el problema de su aplicabilidad por su alto costo. En ese sentido, en 2005 se publica un análisis costo-efectividad proyectando vacunación masiva en Chile, estimando que los gastos de la vacuna se compensan no sólo con la reducción de

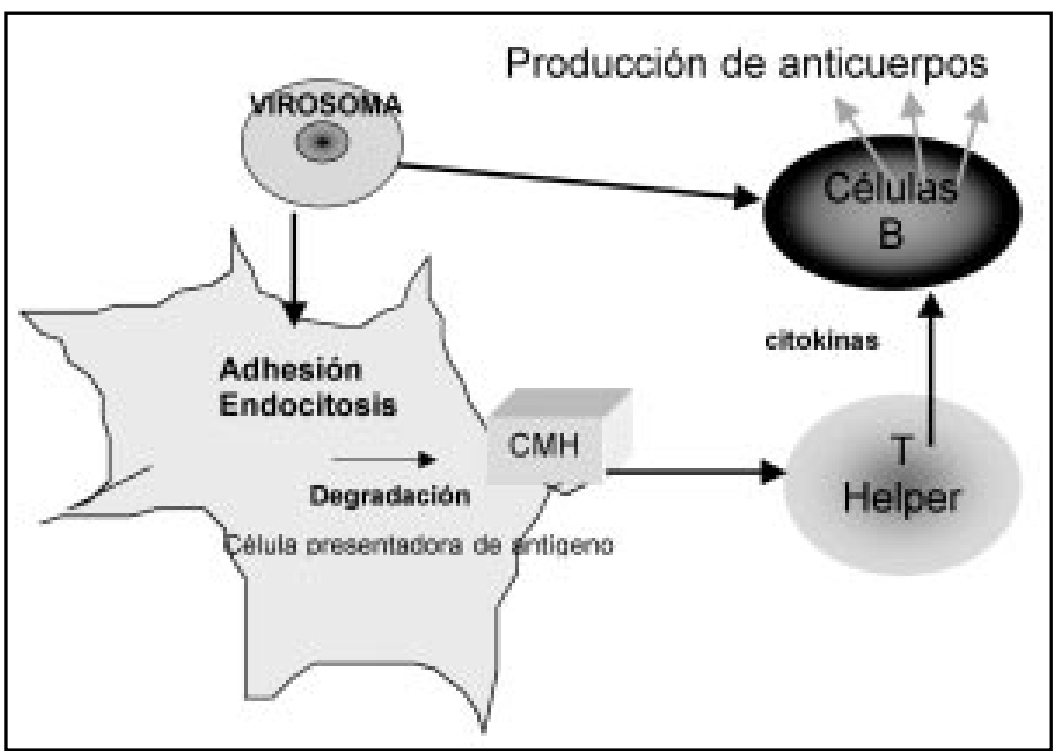

Figura 7. Inducción de anticuerpos por vacuna virosomal contra hepatitis A. 
los costos de la enfermedad, sino también con la prevención de eventos fatales y ajustes de la calidad de vida ${ }^{16}$.

Se hacen necesario nuevos estudios con vacuna contra hepatitis que puedan demostrar ser eficaces en su inmunogenicidad, pero que además impliquen menores costos para su implementación.

\section{HePatitis B}

El virus $B$ es un virus ADN, de estructura compleja. Además de provocar infección aguda puede evolucionar a la cronicidad y al desarrollo de hepatocarcinoma. La infección por virus B no tiene fronteras y se estima que existen más de 2.000 millones de infectados en el mundo, de los cuales 350 millones son portadores del antígeno de superficie (Ag HBs).

En Sudamérica anualmente se reportan 100.000 nuevos casos, con prevalencias de Ag HBs entre 0,4\% y 13\%. Estudios con anticuerpos contra el core (anti-HBc) (Figura 8) revelan la más alta frecuencia en República Dominicana, seguida de Brasil, Venezuela y Argentina. Las más bajas frecuencias corresponden a México y Chile ${ }^{17}$. En el año 1983 se implementó en nuestro país la pesquisa del Ag HBs en los bancos de sangre y en 1991 se publicó una prevalencia de Ag HBs de $0,25 \%$ en donantes ${ }^{18}$.

Pero, ante esta situación epidemiológica para Chile, con prevalencia relativamente baja, es necesa- nio considerar que la vía de transmisión sexual del virus B representa un riesgo importante para nuestra población, ya que está expuesta a un mundo globalizado. Por lo anterior, a pesar de considerarse como enfermedad de notificación obligatoria, los datos aportados al Ministerio de Salud podrían no representar la realidad nacional, por subnotificación, especialmente de casos que no son usuarios de los Servicios de Salud. Entre los años 1991 y 2005 (faltando datos del año 1993), se observó una tendencia al aumento del número de notificaciones hasta el año 2002 (Figura 9) y luego una caída progresiva hasta el año 2005, pero manteniendo tasas sobre 1,2 por 100.000 habitantes.

La estrategia primaria para prevenir la transmisión del virus de la hepatitis B (VHB) se logra mediante la inmunización universal, la que está siendo implementada en muchos países de América Latina, meta que sólo se ha logrado por poco más de 100 países. En Chile, el 1ํ de julio de 2005 se inició la vacunación contra la hepatitis B para los niños, en 3 dosis a los 2, 4 y 6 meses de edad. Los grupos de riesgo para considerar su vacunación continúan siendo: personal de salud, pacientes en hemodiálisis, o individuos que determine la autoridad de un hospital que se consideren expuestos a esta infección.

La vacuna contra el virus de la hepatitis B tiene alta eficacia. Reduce la incidencia de la hepatitis entre $90 \%$ y $95 \%$ de los vacunados. Después de dos dosis se obtienen títulos protectores sobre 10 $\mathrm{mIU} / \mathrm{ml}$. Sin embargo, entre 5 y 10 años posterio-

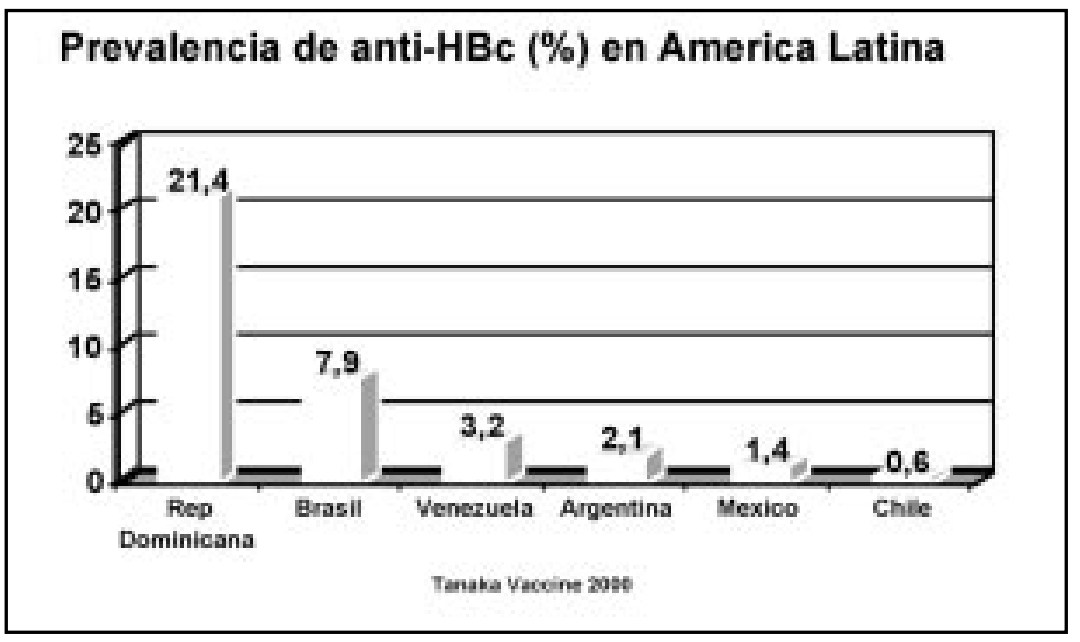

Figura 8. Hepatitis B en América Latina. 


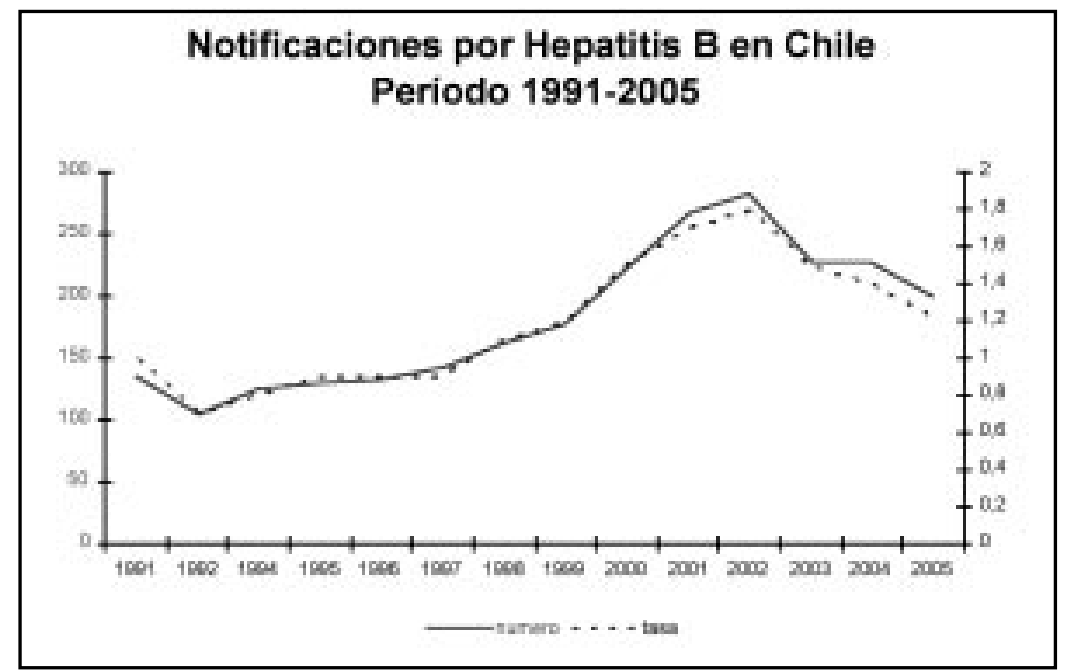

Figura 9. Número y tasa de notificaciones por Hepatitis B en Chile (1991-2005).

res a la inmunización puede haber pérdida de anticuerpos, lo que implica revacunación periódica. Los programas de vacunación a nivel mundial han tenido un enorme impacto, bajando significativamente la incidencia de hepatitis aguda $\mathrm{y}$ hepatocarcinoma ${ }^{19-21}$.

La vacuna contra la hepatitis B disponible en Chile es recombinante. En individuos sanos 3 dosis $(0,1-2,4-6)$ de $10 \mu \mathrm{g}$ en el deltoides generan anticuerpos protectores. Sin embargo, deben considerarse factores que reducen la inmunogenicidad como, por ejemplo: a. Edad sobre 40 años; b. Obesidad; c. Fumadores; d. Sexo masculino; e. Inyección subcutánea; f. Congelamiento de la vacuna; g. Esquema acelerado; h. Hemodiálisis; i. Infección por VIH. Hay, por otro lado, factores que no reducen la inmunogenicidad, como la administración simultánea de inmunoglobulina 0 vacunas combinadas contra hepatitis $\mathrm{A}^{12,22,23}$.

Grupos especiales a considerar son los pacientes cirróticos, los pacientes en espera de trasplante, pacientes trasplantados o con daño hepático crónico no viral, que tienen profundas alteraciones de su sistema inmune, mayor riesgo de infecciones descompensatorias y hepatocarcinoma, por lo que deben ser considerados en los programas de inmunización tanto contra la hepatitis B como eventualmente para la hepatitis A, para lo cual hay que tomar en cuenta la realidad epidemiológica regional. Lamentablemente los pacientes cirróticos no respon- den bien a las vacunas, por lo cual se deben incentivar programas de vacunación en etapas precoces del daño hepático e iniciar la vacunación en cirrosis en etapa Child-Pugh $\mathrm{A}^{24-31}$.

Recientemente, se han incorporado vacunas recombinantes con triple antígeno, que aumentarían la respuesta en individuos no respondedores ${ }^{32,33}$.

\section{HePATITIS C}

El virus de la hepatitis $C$ es el principal responsable de daño hepático crónico por virus en Chile. A partir de 1996 se implementó su pesquisa en los bancos de sangre de nuestro país. Las tasas de notificación de hepatitis $C$ han experimentado un aumento progresivo de 0,24 por 100.000 habitantes en 1994 a 0,99 en 1997 y especialmente en hombres ya que mayoritariamente son ellos los donantes de sangre (Figura 10) ${ }^{34}$.

Los estudios de prevalencia de anti-VHC en cerca de 44.000 donantes de sangre en Santiago de Chile comunicados por diversos autores varían entre $0,22 \%$ y $0,3 \%$. Sin embargo, cerca de $40 \%$ de los pacientes no tienen antecedentes de transfusión. Los genotipos detectados en las muestras ARN-VHC positivas son $1 \mathrm{~b}$ (el más frecuente), 2, 3a y 4/5. Los informes sobre hepatitis C en Chile, en determinados grupos de riesgo, revelan cifras variables. En pacientes con trastornos de coagula- 
Figura 10. Número y tasa de notificaciones por hepatitis $\mathrm{C}$ en Chile (1991-1997).

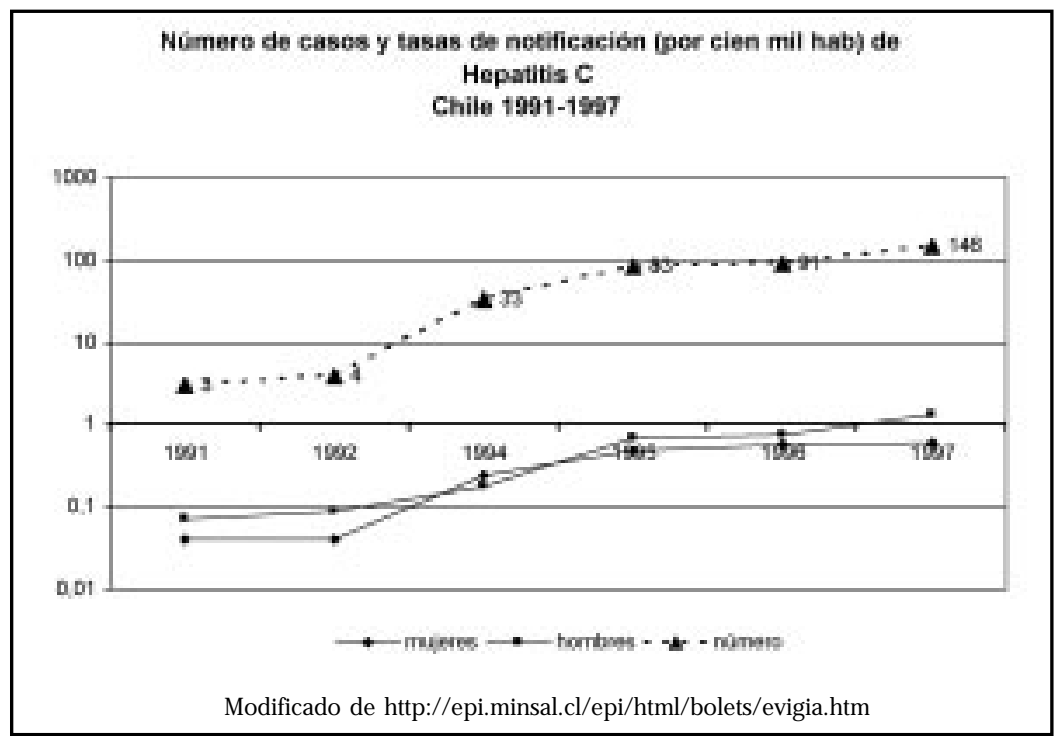

ción, desde $52 \%$ a $88 \%$; trasplantados renales entre $0 \%$ y 34,9\%; pacientes hemodializados de $30 \%$ a $54 \%$; en pacientes con enfermedad hepática crónica no alcohólica 52\%; en portadores de hepatocarcinoma 48\%; en porfiria cutánea tarda $53 \%$; y en leucemia linfoblástica aguda $12 \% 35-42$. Nuevos estudios de prevalencia confirmados con RIBA y publicados en 2005 revelaron 0,83\%, sugiriendo además que el peak de infección en Chile ocurrió entre 30 y 50 años atrás ${ }^{43}$.

La situación epidemiológica de la hepatitis por virus $\mathrm{C}$ en Chile, en esta última década, está revelando la enorme importancia de esta infección en el desarrollo de un daño hepático crónico, al que se agrega la alta prevalencia del genotipo $1 \mathrm{~b}$ que no responde adecuadamente a la terapia y evoluciona con mayor gravedad. En casi la mitad de los pacientes no es posible determinar un factor de riesgo definido y, en Chile, esta patología es la más frecuente indicación de trasplante hepático, como ya está ocurriendo en muchas regiones del mundo ${ }^{44}$.

Por la notable capacidad de variaciones de su genoma, dando lugar a cuasiespecies, se ha dificultado la elaboración de una vacuna aplicable al hombre.

\section{HePATITIS E}

Su vía principal de infección es similar a la hepatitis A. Está estrechamente relacionada con las condiciones sanitarias y constituye un serio problema de salud en países como India con prevalencias entre $24 \%$ y $29 \%$, o en Egipto, donde puede sobrepasar $60 \%{ }^{45,46}$.

De acuerdo a estudios efectuados hace más de una década en donantes de sangre de la Región Metropolitana y de la décima Región, la hepatitis por virus E en nuestro país presenta una prevalencia intermedia entre $4 \%$ y $8 \% 47,48$.

Es difícil obtener información sobre la incidencia de hepatitis aguda por virus E en Chile. Hay comunicaciones de casos aislados, en donde se ha utilizado anti-VHE IgG y anti-VHE IgM ${ }^{49,50}$. Debería investigarse cuando todos los marcadores para los virus de hepatitis A, B y C sean negativos.

En la notificación obligatoria de los casos de hepatitis aguda, obtenidas de los reportes del Ministerio de Salud, pudieran estar incluidos pacientes con hepatitis $E$, ya que por un lado son indistinguibles los casos unos de otros y porque en la mayoría no se exige el diagnóstico específico de la hepatitis A con anti-VHA IgM.

En 1997 se aisló el virus de la hepatitis E en cerdos (swine HEV), que reacciona en forma cruzada con el anti-VHE humano ${ }^{51}$. Estudios efectuados en Brasil reportan una prevalencia de anti-HVE en cerdos entre $63 \%$ y $95 \% 52$. Por otro lado, veterinarios y cuidadores de predios porcinos presentan 1,5 veces más alta prevalencia de estos anticuerpos que donantes de sangre ${ }^{53}$. 
Estudios en predios porcinos de las zonas central y sur de Chile han detectado en esta especie prevalencias entre 0,6\% a 9,5\% ${ }^{54}$. En Japón se ha encontrado identidad genómica en $99,7 \%$ del VHE de jabalíes y ciervos con aislados de VHE humano que consumieron dicha carne, sugiriendo esa fuente de contagio ${ }^{55}$. Numerosas líneas de investigación en estas áreas abren la posibilidad que la infección por el VHE sea zoonótica.

En Chile se requieren más proyectos destinados a evaluar el impacto que podría tener esta infección en seres humanos y su relación con otras especies animales.

\section{CONSIDERACIONES FINALES}

Los antecedentes disponibles respecto de la hepatitis A permiten concluir que su incidencia general está disminuyendo, con un claro desplazamiento a edades superiores, revelando también que ha aumentado la

\section{REFERENCIAS}

1. Boletín Electrónico Mensual (http://epi.minsal.cl/ epi/html/bolets/ evigia.htm)

2. IbarRa H, Riedemann S. Siegel F, Toledo C, ReinharDT G. Hepatitis aguda por virus A, E y no A-E en adultos chilenos a fines de los 90. Rev Méd Chile 2001; 129: 523-30.

3. Zacarías J, Rakeia J, Riveros C, Brink C. Anticuerpos de hepatitis $« A »$. Prevalencia en niños aparentemente sanos y con hepatitis aguda. Rev Méd Chile 1981; 109: 833-6.

4. Lagos R, Potin M, Muñoz A, Abrego P, San Martín O, URETA A et al. Anticuerpos séricos contra el virus hepatitis A en sujetos de nivel socioeconómico medio y bajo, en comunas urbanas de Santiago. Rev Méd Chile 1999; 127: 429-36.

5. Ibarra H, Riedemann S, Reinhardt G, HochsteinMintzel V, Froesner G. Anticuerpos de hepatitis A. Prevalencia en niños de dos áreas rurales en Chile. Rev Méd Chile 1988; 116: 1115-18.

6. Riedemann S, IbarRa $H$, Reinhardt G, Froesner G, Safari A. Prevalencia de anticuerpos anti-hepatitis A en escolares en la década actual. Rev Méd Chile 1998; 126: 1161-64.

7. Riedemann S, Hochstein-Mintzel V, Reinhardt G. Prevalencia de Hepatitis A y B en la población de población que no tiene inmunidad. Esto posiciona a Chile como un país en transición epidemiológica respecto de este tipo de hepatitis y podńa poner en evidencia la «eoná de la higiene $\$ 6,57$ en cuanto a que en este ambiente más estéril» se incrementen las enfermedades con componente autoinmune por respuesta anormal de linfocitos $\mathrm{T}^{58}$.

Es necesario incentivar estrategias para poner al alcance de nuestra población, medidas de prevención eficaces, como son las vacunas específicas contra la hepatitis A.

La hepatitis E requiere más estudios epidemiológicos y su investigación en especies animales en Chile.

La hepatitis B puede estar estabilizada 0 en aumento no pesquisado por subnotificación y debiera continuarse con la inmunización en grupos de riesgo.

Hay un aumento exponencial de la hepatitis C, que puede llegar a ser la principal causa de daño hepático crónico, para lo cual deben implementarse medidas para su manejo, especialmente ante la posibilidad de trasplante hepático.

Valdivia. Estudio seroepidemiológico. Rev Méd Chile 1984; 112: 672-74.

8. Ibarra H, Riedemann S, Pradov Reinhardt G, Vega I, Potin M et al. Estado actual de inmunidad para hepatitis por virus A en diversos grupos de adultos. Rev Méd Chile 1999; 127: 1165-68.

9. Fix AD, Martin OS, GaLicchio I, Vial PA, Lagos R. Age-specific prevalence of antibodies to hepatitis A in Santiago, Chile: risk factors and shift in age of infection among children and young adults. Am J Trop Med Hyg 2002; 66: 628-32.

10. IbarRa $H$, Riedemann $S$, Toledo C. Seguimiento de anticuerpos contra hepatitis A y E en una cohorte de niños de bajo nivel socioeconómico. Rev Méd Chile 2006; 134: 139-44.

11. Riedemann S, Reinhardt G, Froesner G, Ibarra $H$, Moraleda L, Hering V et al. Placebo-Controlled efficacy study hepatitis A vaccine in Valdivia, Chile. Vaccine 1992; 10 suppl 11: 152-55.

12. Prado V, Ruedemann S, Ibarra H, Potin M. Immunogenicity and reactogenicity of a combined hepatitis $A$ and $B$ vaccine in healthy Chilean subjects. Int J Infect Dis 2002; 6: 129-33.

13. Lagos R, Muñoz A, Dumas R, Pichon S, Zambrano B, LeVINE M ET AL. Immunological priming of one dose of inactivated hepatitis A vaccine given during the first year of life in presence of 
maternal antibodies. Vaccine 2003; 21: 3730-33.

14. Ruedemann S, Reinhardt G, IbarRa H, Froesner G. Immunogenicity and safety of a virosomal hepatitis A vaccine (Epaxal ${ }^{\circledR}$ ) in healthy toddlers and children in Chile. Acta Paediatr 2004; 93: 412-14.

15. Mayorga Pérez O, Herzog C, Ze山meyer M, Loaisiga A, Froesner G, Egger M. Efficacy of virosome hepatitis A vaccine in toddlers in Nicaragua: randomized placebo-controlled trial. J Infect Dis 2003; 188: 671-77.

16. Valenzuela MT, Jacobs RJ, Arteaga O, Navarrete MS, MEYerhoff AS, InNIS BL. Cost-effectiveness of universal childhood hepatitis A vaccination in Chile. Vaccine 2005; 23: 4110-19.

17. TANAKA J. Hepatitis B epidemiology in Latin America. Vaccine 2000; 18 Suppl 1: S17-9.

18. Brahm J, Hurtado C, Latorre R, Velasco M, LarronDo M, ORREGo E ET al. Infection by hepatitis B virus in blood donors in Chile. A prospective study (1988-1990). Rev Méd Chile 1991; 119: 354.

19. Da Vima G, Piccinino F, Scolastico C, Fusco M, PICCININO R, SEPE A. Long-term epidemiological survey of hepatitis B virus infection in a hyperendemic area (Afragola, Southem Italy): results of a pilot vaccination project. Res Virol 1998; 149: 263-70.

20. CHANg MH. Decreasing incidence of hepatocellular carcinoma among children following universal hepatitis B immunization. Liver Int 2003; 23: 309-14.

21. Goldstein ST, Zhou F, Hadier SC, Bell BP, Mast EE, Margols HS. A mathematical model to estimate global hepatitis B disease burden and vaccination impact. Int J Epidemiol 2005; 34: 1329-39.

22. Fisman DN, Agrawal D, Leder K. The effect of age on immunologic response to recombinant hepatitis B vaccine: a meta-analysis. Clin Infect Dis 2002; 35: 1368-75.

23. Lemon SM, Thomas DL. Vaccines to prevent viral hepatitis. N Engl J Med 1997; 336: 196-204.

24. ReIss G, KeEFFE EB. Review article: hepatitis vaccination in patients with chronic liver disease. Aliment Pharmacol Ther 2004; 19: 715-27.

25. Arguedas MR, Mc Guire BM, Faшon MB. Implementation of vaccination in patients with cirrhosis. Dig Dis Sci 2002; 47: 384-87.

26. Dominguez M, Barcena R, García M, López SanroMAN A, Nuno J. Vaccination against hepatitis B virus in cirrhotic patients on liver transplant waiting list. Liver Transpl 2000; 6: 440-2.

27. Arstan M, Wiesner RH, Sievers C, Egan K, Zein NN. Double-dose accelerated hepatitis $B$ vaccine in patients with end-stage liver disease. Liver Transpl 2001; 7: 314-20.

28. Loinaz C, De Juanes JR, González EM, López A, LumbreRAs C, Gómez R eT aL. Hepatitis B vaccination results in 140 liver transplant recipients. Hepatogastroenterology 1997; 44: 235-8.

29. Horiander JC, Boyie N, Manam R, Schenk R, Herring $\mathrm{S}$, Kwo PY ET AL. Vaccination against hepatitis B in patients with chronic liver disease awaiting liver transplantation. Am J Med Sci 1999; 318: 304-7.

30. Arguedas MR, Johnson A, Eloubeid MA, Fallon MB. Immunogenicity of hepatitis A vaccination in decompensated cirrhotic patients. Hepatology 2001; 34: 28-31.

31. Angelico M, Di Paolo D, Trinito MO, Petrolati A, Araco A, Zazza S et al. Failure of a reinforced triple course of hepatitis $B$ vaccination in patients transplanted for HBV-related cirrhosis. Hepatology 2002; 35: 176-81.

32. Zuckerman JN, Zuckerman AJ, Symington I, Du W, WiшAms A, Dickson B et al. Evaluation of a new hepatitis $B$ triple-antigen vaccine in inadequate responders to current vaccines. Hepatology 2001; 34: 798-802.

33. Young MD, Schneider DL, Zuckerman AJ, Du W, DiCKSON B, MADDREY WC ET AL. Adult hepatitis B vaccination using a novel triple antigen recombinant vaccine. Hepatology 2001; 34: 372-6.

34. http:// epi.minsal.cl/epi/html/public/hepat/ situacionhepatitisbc.htm

35. Wolff C, Jirón MI, Elgueta R, Vera M, Toriello L, Martínez L et al. Prevalencia de anticuerpos anti virus $\mathrm{C}$ de la hepatitis en dadores de sangre. Análisis de resultados confirmados. Rev Méd Chile 1996; 124: 615-16.

36. Muñoz G, Velasco M, Thiers V, Hurtado C, Brahm J, LaRRondo-LLLO M ET al. Prevalencia y genotipos del virus de la hepatitis c en donantes de sangre y en pacientes con enfermedad hepática crónica y hepatocarcinoma en población chilena. Rev Méd Chile 1998; 126: 1035-42.

37. Armas Merino R, Wolf F, Soto R, Jirón MI, Parraguez A. El virus $C$ de la hepatitis y las enfermedades que produce. Rev Méd Chile 1999; 127: 1240-54.

38. Vega I, León A, Zolezzi P, IbarRa H, Faúndez C, Montecinos J et al. Virus de la hepatitis $C$ en un grupo de pacientes hematológicos y oncohematológicos. Rev Méd Chile 2001; 129: 18-22.

39. Castilo I, Díaz P, Inostroza J, Espinoza R, MilaQueo L, Calderara M et al. Prevalencia de anticuer- 
pos del virus de la hepatitis $C$ en hemodializados crónicos y trasplantados renales. Rev Méd Chile 1993; 121: 1024-8.

40. Ibarra H, Mezzano S, Ruedemann S, Toledo C, ARdiles L, Reinhardt G et al. Virus de hepatitis C y trasplante renal (Carta al Editor). Rev Méd Chile 1992; 120: 81-2.

41. Alegría S, Morales M, Vildósola J, Hurtado C, BRAHM J. Infección con los virus de la hepatitis B y $C$ en niños con trastornos congénitos de la coalgulación. Rev Méd Chile 1994; 122: 638-42.

42. Soza A, Arrese M, González R, Alvarez M, Pérez RM, Cortés P ET AL. Clinical and epidemiological features of 147 Chilean patients with chronic hepatitis C. Ann Hepatol 2004; 3: 146-51.

43. González R, Soza A, Hernández V, Pérez RM, Alvarez M, Morales A et al. Incidence and prevalence of hepatitis $C$ virus infection in Chile. Ann Hepatol 2005; 4: 127-30.

44. Soza A, López-Lastra M. Hepatitis C en Chile: Magnitud del problema. Rev Méd Chile 2006; 134: 777-88.

45. Mathur P, Arora NK, Panda SK, Kapoor SK, JAILKHANI BL, IRSHAD M. Sero-epidemiology of hepatitis $\mathrm{E}$ virus (HEV) in urban and rural children of North India. Indian Pediatr 2001; 38: 461-75.

46. Fix AD, Abdel-Hamid M, Purcell RH, Shehata MH, Abdel-Aziz F, Mikhail $N$ et al. Prevalence of antibodies to hepatitis $\mathrm{E}$ in two rural Egyptian communities. Am J Trop Med Hyg 2000; 62: 51923.

47. Brahm J, Hurtado C, Moraga M, Gil MC, Velasco M, Alegría S et al. Infección con el virus de la hepatitis E en Chile. Rev Méd Chile 1996; 124: 947-49.

48. Ibarra H, Riedemann S, Reinhardt G, Frick P, Siegel F, Toledo C et al. Prevalencia de anticuerpos del virus Hepatitis $\mathrm{E}$ en donantes de bancos de sangre y otros grupos de población, en la $\mathrm{X}$ región, Chile. Rev Méd Chile 1997; 125: 275-78.
49. Ibarra H, Riedemann S, Siegel F, Toledo C, ReinharDT G. Hepatitis aguda por virus A, E y no A-E en adultos chilenos a fines de los 90. Rev Méd Chile 2001; 129: 523-30.

50. Hurtado C, Muñoz G, Brahm J. Anti-VHE IgM en casos de infección por el virus hepatitis E. Rev Méd Chile 2005; 133: 645-47.

51. Meng XJ, Purcell RH, Halbur PG, Lehman JR, Webb DM, TSAREVA TS ET AL. A novel virus in swine closely related to the human hepatitis E virus. Proc Natl Sci USA 1997; 94: 9860-65.

52. Vitral CL, Pinto MA, Lewis-Ximenez LL, Khudyakov YE, Dos Santos DR, Gastar AM. Serological evidence of hepatitis $E$ virus infection in different animal species from the Southeast of Brazil. Mem Inst Oswaldo Cruz 2005; 100: 117-22.

53. Meng XJ, Wiseman B, Elvinger F, Guenette DK, Tотн TE, Engle RE et al. Prevalence of Antibodies to Hepatitis E Virus in Veterinarians Working with Swine and in Normal Blood Donors in the United States and other Countries. J Clin Microbiol 2002; 40: 117-22.

54. Reinhardt G, IbarRa H, Ruedemann S, Vega I. Estudio serológico preliminar de hepatitis $\mathrm{E}$ en cerdos en Chile. Arch Med Vet 2003; 2: 233-36.

55. TaKahashi K, Kitajima N, Abe N, Mishiro S. Complete or near complete nucleotide sequences of hepatitis E virus genome recovered from a wild boar, a deer, and tour patients who ate the deer. Virology 2004; 330: 501-5.

56. Valdivia G. Transición epidemiológica: la otra cara de la moneda (editorial). Rev Méd Chile 2006; 134: 675-78.

57. Luque C, Cisternas F, Araya M. Cambios del patrón de enfermedad en la postransición epidemiológica en salud en Chile, 1950-2003. Rev Méd Chile 2006; 134: 703-12.

58. McIntire JJ, Umetsu SE, Macaubas C, Hoyte EG, Cinnioglu C, CavaLi-Sforza LL et al. Immunology: hepatitis A virus link to atopic disease. Nature 2003; 425: 576. 